\title{
Clinical Significance of Ambulatory Blood Pressure Monitoring
}

\section{Evaluation of Severity of Hypertension, Efficacy of Treatment and Effects on Nighttime Blood Pressure}

\author{
Shigehiro Katayama, M.D., Yoshiko Maruno, M.D., \\ Akira Itabashi, M.D., Munemichi InaBa, M.D., \\ Akira Omoto, M.D., and Jun IsHII, M.D.
}

SUMmary

Blood pressure (BP) obtained by the physician in his office and ambulatory BP recorded every hour throughout 24 hours with a noninvasive automated BP monitoring device were compared in 10 normotensives and 162 hypertensives. Casual BPs significantly correlated with averages in ambulatory $B P_{s}(A B P s)$ throughout the whole day, day $(7 \mathrm{am}-10 \mathrm{pm}$ ) and night $(0-5 \mathrm{am})$. However, it was noted that 6 of 10 normotensives and all of the moderate to severe hypertensives had ABPs of more than $150 / 90 \mathrm{mmHg}$ at least once during the 24-hour period. The incidence of $\mathrm{ABP}_{\mathrm{s}}$ greater than $150 / 90 \mathrm{mmHg}$ among all readings was higher in untreated and treated hypertensives with diastolic BPs in the office of more than $105 \mathrm{mmHg}$, and, when checked along with the clock time, higher not only in the morning but also in the evening. On the other hand, one-third or one-fifth of treated hypertensives with diastolic office BPs less than $90 \mathrm{mmHg}$ or between 90 and $105 \mathrm{mmHg}$ respectively had ABPs less than $150 / 90 \mathrm{mmHg}$ throughout the whole day. When the effect of nicardipine $(60 \mathrm{mg}$, t.i.d.) or slow-release nifedipine $(27.3 \pm 3.0 \mathrm{mg}$, b.i.d.) on minimum $\mathrm{BP}$ during the night was analyzed, long-acting nifedipine decreased BP throughout the night to levels not significantly different from normotensive controls, whereas short-acting nicardipine did not affect nighttime BPs. These results suggest that simple ABP monitoring throughout the day gives us useful information to evaluate the severity of hypertension and the efficacy of antihypertensive medication as well as to avoid overtreatment with long-acting hypotensive agents resulting in a great fall in BP during sleep.

\section{Additional Indexing Words :}

Essential hypertension

Mild hypertension

Ambulatory blood pressure monitoring Nifedipine Nicardipine

From the Fourth Department of Medicine, Saitama Medical School, Saitama, Japan.

Address for correspondence: Shigehiro Katayama, M.D., Fourth Department of Medicine, Saitama Medical School, Moroyama-cho, Irumamgun, Saitama 350-04, Japan.

Received for publication March 9, 1990.

Accepted September 6, 1990. 
ITH the advent of a handy device for noninvasive automated blood pressure monitoring (ABPM), there is now an abundance of evidence that $\mathrm{ABP}$ is a better marker for the efficacy of antihypertensive medication and the potential risk of cardiovascular complications than BP determined in the physician's office. ${ }^{1,2)}$ Ambulatory or self-monitored BP at home is generally believed to be lower than BP recorded in physicians' offices. ${ }^{2)-4)}$ Waeber et $\mathrm{al}^{53}$ recently reported that half of the patients with BP greater than $95 \mathrm{mmHg}$ in physicians' offices, despite antihypertensive treatment, had ambulatory BPs of $90 \mathrm{mmHg}$ or less, and that new antihypertensive therapy over a 3 month period decreased their mean daytime diastolic BP to an average of $79 \mathrm{mmHg}$, indicating that, if we treat hypertensives based on only traditional $\mathrm{BP}$ readings obtained in the office, the possibility of overtreatment may exist in some of the patients. In addition, there is increasing evidence that nighttime BP decreases in accordance with circadian rhythms even in hypertensives. Because of the development of antihypertensive drugs with a long half-life as well as progress in drug delivery systems, long-acting antihypertensive drugs have become available. These drugs may lower not only daytime BP but nighttime BP as well. Therefore, we monitored 24-hour BP with a noninvasive monitoring system in normotensives as well as hypertensives, with and without treatment, while they pursued normal activities at home or in the workplace. Our study was designed to compare office BP with $A B P$, investigate the efficacy of therapy and shed light on nighttime BP during treatment with long-acting antihypertensive drugs.

\section{Subjects And Methods}

This study involved a total of 166 patients with essential hypertension with $(n=104$, mean age; $56.6 \pm 1.8(\mathrm{SE})$ years old $)$ and without $(n=58$, mean age; $52.5 \pm 1.9$ years old) antihypertensive medication as well as 10 healthy normotensives aged $47.2 \pm 5.1$ years, who had never been noted to have hypertension. Each patient had a full clinical examination and laboratory screening tests to exclude secondary hypertension. For the classification of blood pressure levels, the criteria used were those recommended by the Joint National Committee on Detection, Evaluation and Treatment of High Blood Pressure. However, referred first visit hypertensive patients who had diastolic BP of less than $90 \mathrm{mmHg}$ in our clinic were included in this study. After casual office sitting BPs and heart rates (SBPOFFICE, DBPOFFICE, HROFFICE) were obtained in the clinic between 9 am and noon, automated ABPM was performed every hour during a 24-hour period using an ABPM630 (Nihon Colin, Komaki, Japan), the accuracy of which was evaluated by 
comparing oscillometric readings with Korotkoff's readings at the same site. The subjects were asked to perform their normal daily activities, including those performed during a regular working day. Oscillometric readings of systolic and diastolic BP and pulse rate were obtained at 1-hour intervals throughout the 24-hour period. Tracings were analyzed only if at least 20 time points were available. Actually, the data from 4 hypertensives were discarded. The following analyses of systolic (SBP), diastolic (DBP) and mean $\mathrm{BP}(\mathrm{MBP})$ and heart rate $(\mathrm{HR})$ were performed using a microcomputer: average of all readings obtained during the 24-hour monitoring period (SBPWHOLE, DBPWHOLE, MBPWHOLE, HRWHOLE), average of the readings obtained during the daytime from 7 am to $10 \mathrm{pm}$ (SBPDAY, DBPDAY, MBPDAY, HRDAY), average of all measurements during sleep from 0 am to 5 am (SBPNIGHT, DBPNIGHT, MBPNIGHT, HRNIGHT) and minimum BP during sleep. The same parameters in the patients treated with nicardipine (20 mg 3 times a day, $\mathrm{n}=11$, mean age; $55.0 \pm 2.7$ years old) or slow-release nifedipine (10-20 mg twice a day, $\mathrm{n}=22$, mean age; $57.8 \pm 2.6$ years old) werc analyzcd as well.

All data are expressed as the mean \pm SE. Standard statistical analyses, paired or unpaired Student's t-test, correlation coefficients, and Fisher's probability test, were used to analyze the data.

\section{Results}

Oscillometric measurements significantly correlated with Korotkoff's readings obtained from the same arm at the same site (for SBP, $r=0.961$, $\mathrm{p}<0.01$; for DBP, $\mathrm{r}=0.874, \mathrm{p}<0.01, \mathrm{n}=32 \mathrm{each})$. The absolute difference from Korotkoff's value was $-0.63 \pm 1.8 \mathrm{mmHg}$ in SBP and $-0.47 \pm 5.0$ $\mathrm{mmHg}$ in DBP.

Figure 1 shows the circadian pattern of BP in normotensives and untreated hypertensives. The circadian BP pattern in both groups showed the highest values during the day and lowest values at night. The highest values were usually found in the morning or in the afternoon and the lowest values were generally found between 2-3 am. A comparison between office BPs in hypertensives and average BPs obtained during ABPM is presented in Table $\mathrm{I}$ and Fig. 2. SBPOFFICE and DBPOFFICE were significantly correlated with ambulatory SBP or DBP throughout the whole day, day and night. In addition, HROFFICE was also significantly correlated with ambulatory HR during all time periods.

To determine the effect of antihypertensive medication, patients were separated into 6 groups according to office DBP, i.e., less than 90, 90-105, 


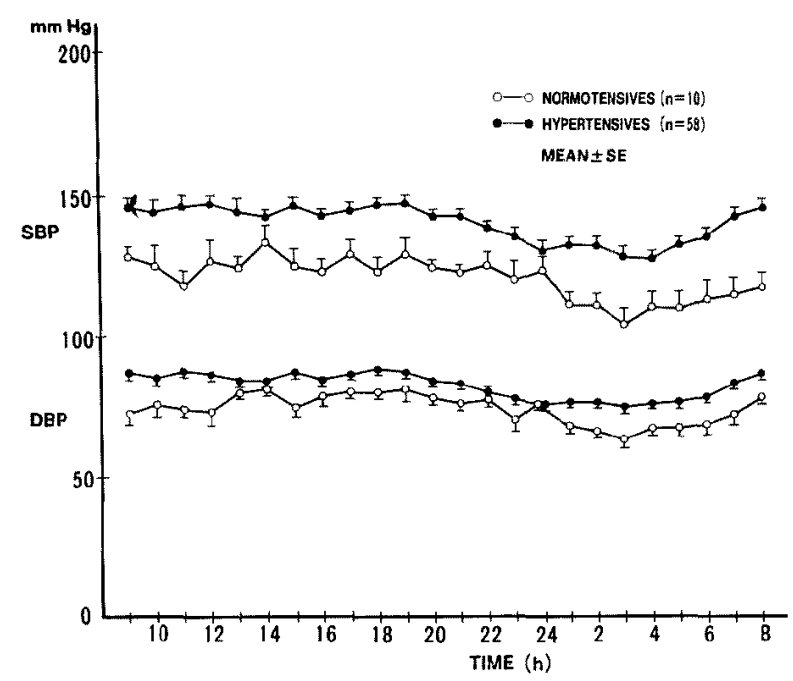

Fig. 1. Circadian changes in systolic (SBP) and diastolic (DBP) blood pressure obtained by ambulatory blood pressure monitoring in normotensives (open circles) and untreated hypertensives (closed circles).

Table I. Correlation between BP Obtained in the Office and Ambulatory BP Recorded Every Hour by an Automated Device

\begin{tabular}{l|c|c|c}
\hline & SBPOFFICE & DBPOFFICE & HROFFICE \\
\hline SBPWHOLE & $0.527^{* *}$ & $0.304^{* *}$ & 0.052 \\
SBPDAY & $0.577^{* *}$ & $0.352^{* *}$ & 0.048 \\
SBPNIGHT & $0.412^{* *}$ & $0.231^{* *}$ & 0.069 \\
DBPWHOLE & $0.444^{* *}$ & $0.403^{* *}$ & 0.110 \\
DBPDAY & $0.498^{* *}$ & $0.437^{* *}$ & 0.112 \\
DBPNIGHT & $0.353^{* *}$ & $0.294^{* *}$ & 0.115 \\
HRWHOLE & 0.080 & $0.227 * *$ & $0.558^{* *}$ \\
HRDAY & 0.086 & $0.209 * *$ & $0.529 * *$ \\
HRNIGHT & 0.122 & $0.190^{*}$ & $0.450 * *$
\end{tabular}

** $\mathrm{p}<0.01, * \mathrm{p}<0.05$

more than $105 \mathrm{mmHg}$, and antihypertensive drugs, present or absent. Results including normotensives are shown in Fig. 3. The difference between SBPOFFICE and SBPWHOLE or SBPDAY was about 20 or $10 \mathrm{mmHg}$ in hypertensives with SBPOFFIGE less than $105 \mathrm{mmHg}$, and about 30 and $20 \mathrm{mmHg}$ in moderate or severe hypertensives. The difference between DBP obtained in the office and DBPWHOLE or DBPDAY was the same as in patients with DBPOFFICE less than $90 \mathrm{mmHg}$ or higher by 10 or 20 $\mathrm{mmHg}$ in hypertensives with DBPOFFICE between 90 and $105 \mathrm{mmHg}$, or 


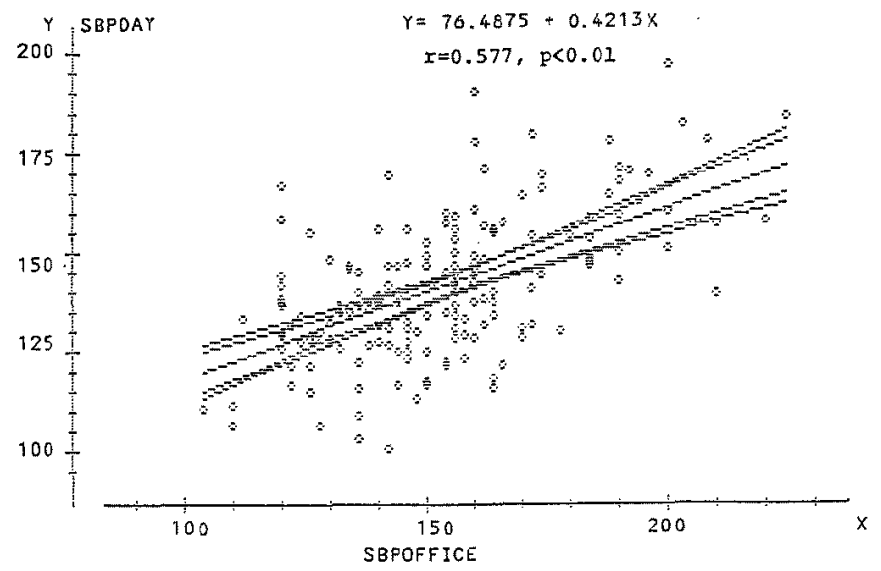

Fig. 2. Correlation between SBP obtained in the office (SBPOFFICE) and mean SBP recorded by ambulatory blood pressure monitoring from $7 \mathrm{am}$ to $10 \mathrm{pm}$ (SBPDAY).
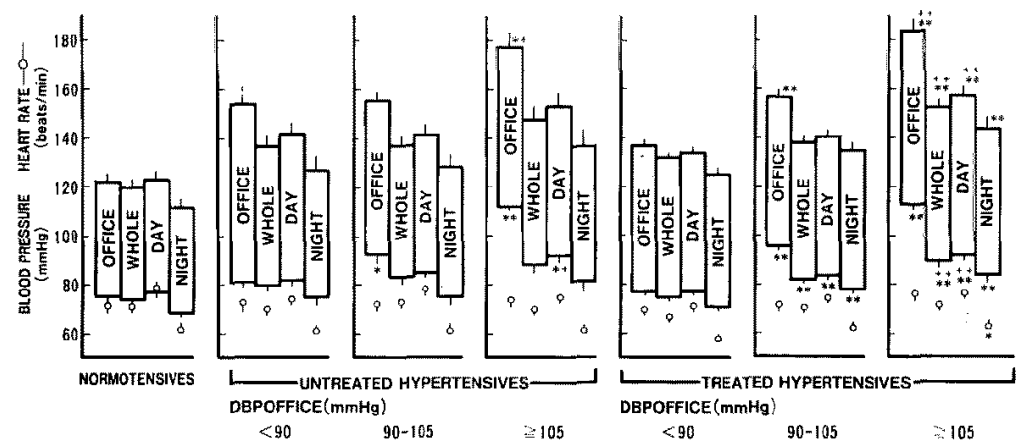

Fig. 3. Casual blood pressures obtained in the office (OFFICE) and by ambulatory blood pressure obtained during the whole day (WHOLE), the day (7 am-10 pm; DAY) and the night (0-5 am; NIGHT) in normotensives and hypertensives with or without medication. Heart rate is shown by a circle. Each value indicates the mean \pm SE. ** or *: $p<0.01$ or $\mathrm{p}<0.05$ vs the untreated or treated group with DBPOFFICE $<90 \mathrm{mmHg},{ }^{++}$or ${ }^{+}: \mathrm{p}<0.01$ or $p<0.05$ vs the untreated or treated group with DBPOFFICE between 90 and $105 \mathrm{mmHg}$, respectively.

more than $105 \mathrm{mmHg}$, respectively. Among these groups, of interest is the observation that $60 \%$ of normotensives and all of the moderate to severe hypertensives with DBPOFFICE more than $105 \mathrm{mmHg}$, whether or not treated, did show ABP of more than $150 / 90 \mathrm{mmHg}$ at least once during 24hour ABPM as shown in Table II. On the other hand, $34(21.6 \%)$ of the treated hypertensive patients with office DBP less than 90 or between $90-105 \mathrm{mmHg}$ respectively had $\mathrm{ABP}_{\mathrm{s}}$ less than $150 / 90 \mathrm{mmHg}$ throughout 


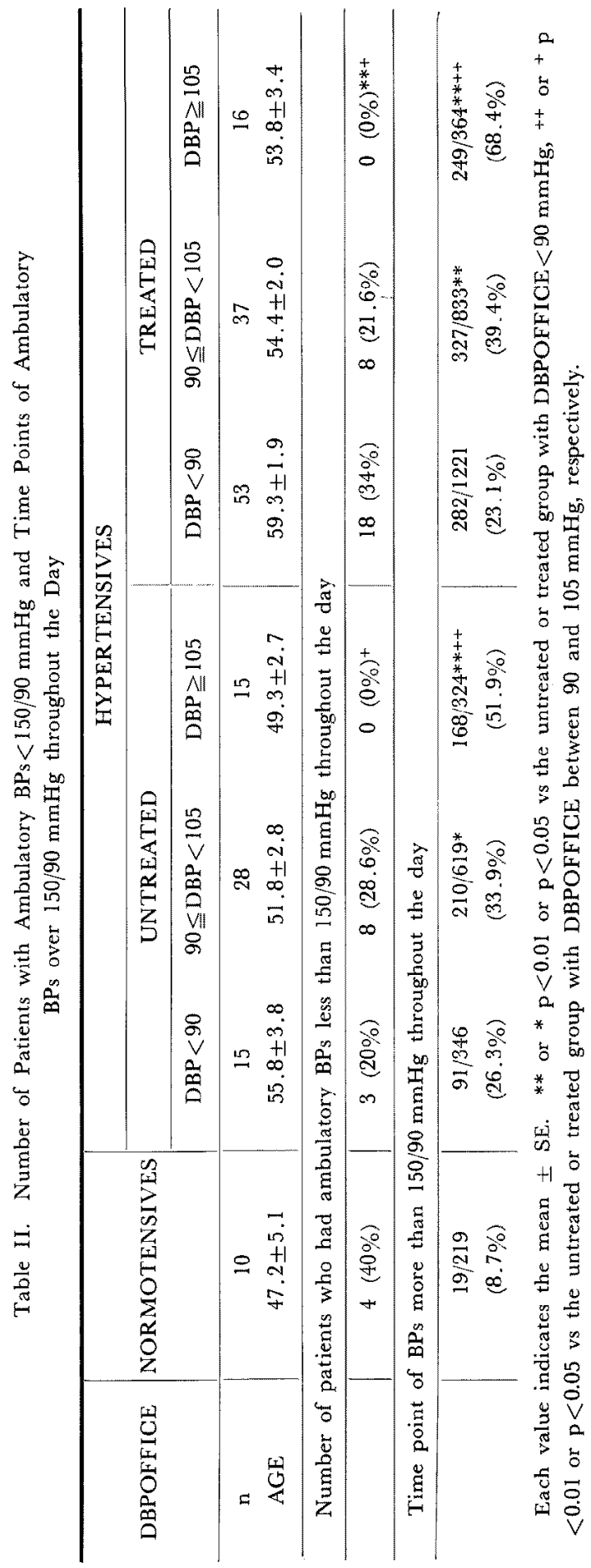




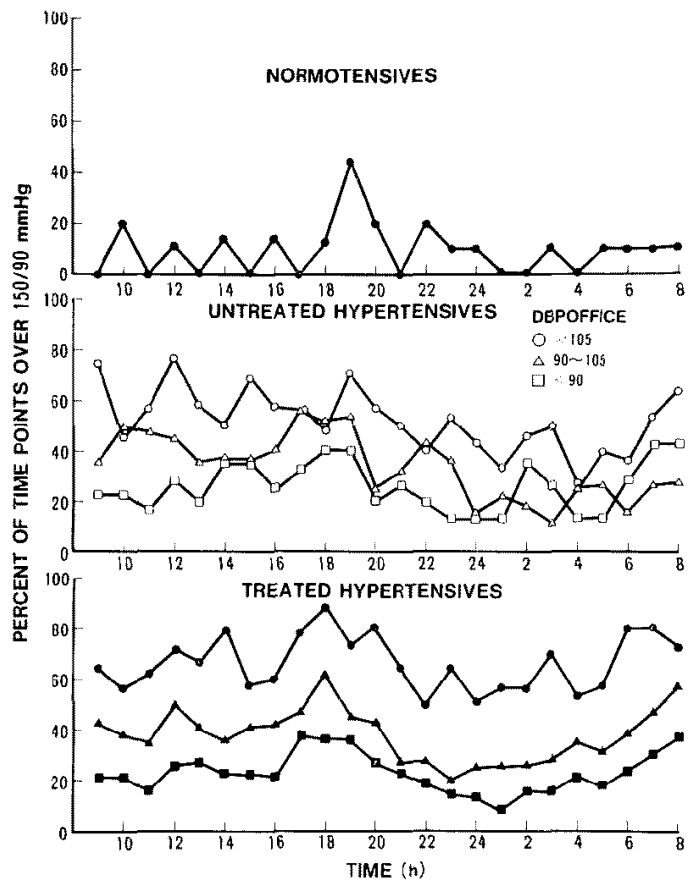

Fig. 4. Percent of time points exceeding $150 \mathrm{mmHg}$ in systolic blood pressure and/or $90 \mathrm{mmHg}$ in diastolic blood pressure in normotensives and hypertensives divided on the basis of the presence or absence of the hypotensive agents, and level of diastolic blood pressure obtained in the office (DBPOFFICE).

the 24-hour period. The incidence of ambulatory BPs greater than 150/90 $\mathrm{mmHg}$ among all readings was significantly higher in the hypertensive groups and highest in the treated group with moderate to severe hypertension. The incidence of $\mathrm{ABP}$ greater than $150 / 90 \mathrm{mmHg}$ along with the clock time is shown in Fig. 4. Even in the normotensives, about half had higher BP in the evening and hypertensives had two peaks in the morning and in the evening.

Minimum BP during the night, on the other hand, is shown in Table III. To see the effect of long-acting antihypertensive medication on nighttime BP, data from hypertensives treated with nicardipine (20 mg 3 times a day) or slow-release nifedipine (10-20 $\mathrm{mg}$ twice a day) are shown in Fig. 5 as MBP. It is evident that nighttime $\mathrm{BP}$ in patients treated with nicardipine was not different from BP in hypertensives without drugs, but significantly higher compared with BP in normotensives between 2 and 7 am, while administration of long-acting nifedipine twice a day (mean dosage 27.3 \pm 3.0 $\mathrm{mg} /$ day) decreased MBP throughout the night to levels which were not signi- 
Table III. Minimum Blood Pressure and Heart Rate during the Night Obtained by ABPM

\begin{tabular}{c|c|c|c|c|c}
\hline & SBP & DBP & Range & HR & Range \\
\hline $\begin{array}{l}\text { Normotensives } \\
\text { Hypertensives untreated }\end{array}$ & $93.3 \pm 4.3$ & $59.6 \pm 2.9$ & $69 / 44-113 / 67$ & $60.5 \pm 3.0$ & $47-73$ \\
DBPOFFICE $<90$ & $107.5 \pm 5.0$ & $65.5 \pm 3.2$ & $89 / 48-142 / 84$ & $62.7 \pm 1.9$ & $54-73$ \\
$90 \leqq$ DBPOFFICE $<105$ & $113.4 \pm 5.2^{* *}$ & $67.9 \pm 2.0$ & $85 / 48-137 / 83$ & $62.3 \pm 1.5$ & $45-80$ \\
DBPOFFICE $\geqq 105$ & $121.9 \pm 6.2^{* *}$ & $72.8 \pm 3.9 *$ & $89 / 54-147 / 83$ & $63.7 \pm 2.8$ & $47-82$ \\
Hypertensives treated & & & & & \\
DBPOFFICE $<90$ & $111.1 \pm 2.7 * *$ & $66.1 \pm 1.7$ & $76 / 45-152 / 82$ & $57.1 \pm 1.2$ & $44-69$ \\
$90 \leqq$ DBPOFFICE $<105$ & $120.0 \pm 2.9 * *+$ & $71.6 \pm 2.2 * *+$ & $78 / 46-150 / 96$ & $62.2 \pm 1.9$ & $39-83$ \\
DBPOFFICE $\geqq 105$ & $122.8 \pm 5.6 * *+$ & $73.0 \pm 3.8 *$ & $80 / 54-153 / 93$ & $63.1 \pm 3.1$ & $47-93$
\end{tabular}

Each value represents the mean $\pm \mathrm{SE}$.

** $\mathrm{p}<0.01$ vs normotensive controls, $* \mathrm{p}<0.05$ vs normotensive controls.

$+p<0.05$ vs treated hypertensives with DBPOFFICE less than $90 \mathrm{mmHg}$.

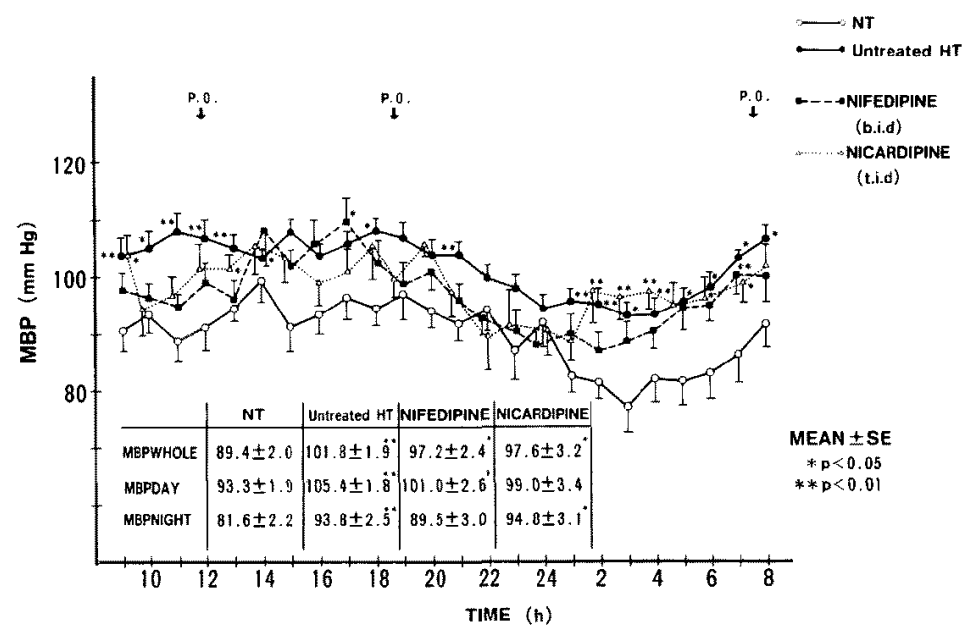

Fig. 5. Circadian variations in mean blood pressure (MBP) obtained by ambulatory blood pressure monitoring in normotensives $(n=10)$, untreated hypertensives $(n=58)$ and hypertensives treated with either nicardipine $20 \mathrm{mg}$ 3 times a day or slow-release nifedipine with a mean dosage of $27.3 \pm 3.0 \mathrm{mg} /$ day (b.i.d.). The arrow indicates the time of drug administration.

ficantly different from those in normotensives.

\section{Discuission}

Our study in the outpatient hypertension clinic revealed a circadian variation in BP which was higher in the daytime and lower during sleep. However, hypertensives, whether or not they were treated with hypotensive 
agents, had two peaks, in the morning and in the evening. Surprisingly, normotensives, who had no history of hypertension, had BPs of more than $150 / 90 \mathrm{mmHg}$ at least once during a 24-h period in 6 of 10 cases and a higher incidence of BP above $150 / 90 \mathrm{mmHg}$ in the evening. This might be attributed to ABPM during the workday, because, at such times in the evening, many people are busy finishing their work at the workplace. Until now, the effect of antihypertensive drugs on BP circadian rhythm has been investigated mainly in inpatients. In such cases, daily activities in the hospital were different from those in the usual workplace.

Secondly, a significant positive correlation of BP at the office with ABPM parameters is reasonable since these arm measurements are essentially the same parameters under different circumstances. Furthermore, ABPM is very reliable in predicting the severity of hypertension, i.e., paticnts with moderate to severe essential hypertension with DBPOFFICE more than 90 $\mathrm{mmHg}$ had ABPM patterns with BP over $150 / 90 \mathrm{mmHg}$ at least once during the 24-h period. Moreover, the difference between BP in the office and ABPM was greater in moderate or severe hypertension than in mild hypertension, $20 \mathrm{mmHg}$ in $\mathrm{SBP}$ and $10 \mathrm{mmHg}$ in $\mathrm{DBP}$, similar to the findings of others. ${ }^{6-9)}$

One more clinically significant role of ABPM may exist in the evaluation of the efficacy of antihypertensive medication. When DBP obtained at the office was lower than $90 \mathrm{mmHg}$ and between 90 and $105 \mathrm{mmHg}$, about one-third and one-fifth, respectively, of the treated patients had BPs less than $150 \mathrm{mmHg}$ systolic and/or $90 \mathrm{mmHg}$ diastolic throughout the day. On the other hand, when DBP in the office exceeded $105 \mathrm{mmHg}$, none of the patients had BPs less than $150 \mathrm{mmHg}$ systolic and/or $90 \mathrm{mmHg}$ diastolic during the 24-h period. On the contrary, it should be noted that, even when DBPOFFICE was between $90-105 \mathrm{mmHg}$ in untreated hypertensives, $28.6 \%$ had lower ABP throughout the day. Based on these observations, DBPOFFICE is not a reliable parameter for estimating overall $\mathrm{BP}$ control in the workplace. This was also evident from the findings that a correlation between $\mathrm{BP}$ at the office and ABPM is rather lower than expected. One of the reasons may be that some patients had much higher BPs in the office than at home or in the workplace, i.e., so-called white coat hypertension. ${ }^{10,11)}$ Our study included first-visit patients. This might be another reason, because alerting responses to a clinic visit wane on repeated measurements and BP declines with repeated clinic visits. ${ }^{6), 12), 13)}$ ABPM is, therefore, extremely effective in excluding such cases and avoiding overtreatment.

The other point to be made in our present study is that we were able to monitor nighttime $\mathrm{BP}$ during sleep with and without antihypertensive 
medication. Of course, BP may fluctuate from beat to beat. Only 6 points during 0-5 am cannot reflect the real minimum BP at night. However, Pomidossi $G$ et $a^{14}$ ) reported that sampling BP every 60 min could estimate the real BP level obtained by intra-arterial recordings, but not BP variability. ABPM based on one or four readings per $h$ on 2 successive days was reported to be indistinguishable. ${ }^{15}$ ) Thus, this time interval may be enough to evaluate the extent to which BP decreased during treatment. Some patients treated with slow-release nifedipine twice a day showed a decrease in BP during the night, while nicardipine administered 3 times a day did not produce such a change. Plasma half-life was reported to be $81 \mathrm{~min}$ for the latter ${ }^{16)}$ and $5-6 \mathrm{~h}$ for the former. ${ }^{17)}$ A greater fall not only in the daytime but also in the nighttime may be harmful to hypertensives with impaired cerebral autoregulation, especially the elderly. Although to what extent the nighttime BP should be decreased by hypotensive agents or whether overtreatment per se involves real risk of cerebral or cardiovascular accidents is not clear at present, ABPM gives us useful information in evaluating severity of hypertension and efficacy of hypotensive agents as well as in avoiding overtreatment resulting in a great fall during not only the daytime but also the nighttime.

\section{REFERENCES}

1. Perloff D, Sokolow M, Cowan R: The prognostic value of ambulatory blood pressures. JAMA 249: 2792, 1983

2. O'Brien, O'Malley K, Fitzgerald D: The value of home and ambulatory blood pressure recording in the management of hypertension. J Hypert 3 (suppl 1): 35, 1985

3. Sleight P: Differences between casual and 24-h blood pressure. J Hypert 3 (suppl 2): S19, 1985

4. Padfield PL, Lindsay BA, McLaren JA, Pricie A, Rademaker M: Changing relation between home and clinic blood pressure measurements: Do home measurements predict clinic hypertension? Lancet II: 322,1987

5. Waeber B, Scherrer U, Petrillo A, Bidiville J, Nassberger J, Waeber G, Hofstetter J, Bruner HR: Are some hypertensive patients overtreated? A prospective study of ambulatory blood pressure recording. Lancet II: 732, 1987

6. Carey RM, Reid RA, Ayers CR: The Charlottesville blood pressure survey: value of repeated blood pressure measurements to determine the prevalence of labile and sustained hypertension. JAMA 236: 847, 1976

7. Medical Research Council Working Party: MRC trial of treatment of mild hypertension: principal results. Br Med J 291: 97, 1985

8. Welin L, Svärdsudd K, Tibblin G: Home blood pressure measurements-feasibility and results compared to office measurements. Acta Med Scand 211: 275, 1982

9. Conway J, Johnston J, Coats A, Somers V, Sleight P: The use of ambulatory blood pressure monitoring to improve the accuracy and reduce the numbers of subjects in clinical trials of antihypertensive agents. J Hypert 6: 111, 1988

10. Nielsen PE, Myschetzky P, Andersen AR, Andersen GS: Home readings of blood pressure in assessment of hypertensive patients. Acta Med Scand 714 (suppl): 147, 1986 
11. Manica G, Parati G, Pomidossi G, Grassi G, Casdei R, Zanchetti A: Alerting reaction and rise in blood pressure during measurement by physician and nurse. Hypertension 9: 209, 1987

12. Australian National Blood Pressure Study Management Committee: The Australian therapeutic trial in mild hypertension. Lancet $\mathbf{I}: 1261,1980$

13. Watson RDS, Lumb R, Young MA, Stallard TJ, Davies P, Littler WA: Variation in cuff blood pressure in untreated outpatients with mild hypertension-implications for initiating antihypertensive treatment. J Hypert 5: 207, 1987

14. Pomidossi G, Parati G, Casdei R, Manica G: Absence of alarm reactions with use of noninvasive blood pressure monitoring device. Clin Exp Hypert (A) 7: 429, 1985

15. Van Egeren LF: Repeated measurements of ambulatory blood pressure. J Hypert 6: 753, 1988

16. Seki T, Takenaka T: Pharmacological evaluation of $\mathrm{YC}-93$, a new vasodilator, in healthy volunteers. Int J Pharmacol 15: 267, 1977

17. Raemsch KD, Sommer J: Pharmacokinetics and metabolism of nifedipine. Hypertension 5 (suppl II): 18, 1983 